\title{
Kompetensi Emosi (Ekspresi dan Pemahaman Emosi) pada Anak Usia Prasekolah
}

\author{
Tiara Erlita \& Zainal Abidin \\ Universitas Padjajaran Bandung
}

\begin{abstract}
Children's emotional competence will affect their psychosocial health. The purpose of this study is to provide an overview of emotional competency (expression and understanding) in preschool children (aged 4-5 years) in kindergarten " $X$ " Jatinangor. This research uses qualitative method with a case study approach. The research subjects were children aged 4-5 years who attended kindergarten ' $X$ " Jatinangor. The research instrument used interviews and observations of the subject as the main participants and interviews with parents amd teachers as secondary participants. Data analysis used thematic analysis. This Study found that emotional competence which includes the subject's ability to express and understand emotions as follows: all subjects could express emotion nonverbally, but not all subjects were able to express emotions they felt verbally and all subjects could understand the emotions that are felt but were still limited in labeling emotions appropriately. Associated with children's limitations in emotional labelling, parents and teachers need to provide an understanding of emotional labels felt by children.
\end{abstract}

Keywords: Emotional Competence; Expression Emotion; Labelling Emotion

\begin{abstract}
Abstrak
Kompetensi emosi anak akan memengaruhi kesehatan psikososialnya. Tujuan dari penelitian ini untuk memberikan gambaran mengenai kompetensi emosi (ekspresi dan pemahaman emosi) pada anak usia prasekolah (usia 4-5 tahun) di Taman Kanak - Kanak "X" Jatinangor. Penelitian ini menggunakan metode penelitian kualitatif dengan pendekatan studi kasus. Subjek penelitian adalah anak usia 4-5 tahun yang bersekolah di TK " $X$ " Jatinangor. Instrument penelitian menggunakan wawancara dan observasi terhadap subjek sebagai partisipan utama dan wawancara terhadap orangtua, guru sebagai partisipan sekunder. Analisa data menggunakan analisa tematik. Penelitian ini menemukan bahwa kompetensi emosi yang mencakup kemampuan subjek dalam mengekspresikan dan memahami emosi sebagai berikut: seluruh subjek dapat mengekspresikan emosi secara non-verbal, akan tetapi tidak semua subjek mampu mengekspresikan emosi yang dirasakannya secara verbal dan semua subjek juga dapat memahami emosi yang dirasakan namun masih terbatas dalam memberikan label emosi secara tepat. Terkait dengan keterbatasan anak dalam memberikan label emosi, maka orang tua dan guru perlu memberikan pemahaman mengenai label emosi yang dirasakan oleh anak
\end{abstract}

Kata kunci: Kompetensi Emosi; Ekspresi Emosi; Label Emosi 
Emosi adalah perasaan atau afeksi yang muncul ketika seseorang sedang berada dalam suatu keadaan atau interaksi yang dianggap penting olehnya, terutama kesejahteraan dirinya (Campos, 2004; Sarni, dkk.,2006 dalam Santrock 2007). Emosi ditampilkan dalam bentuk perilaku yang mengekspresikan kenyamanan atau ketidaknyamanan seseorang terhadap keadaan atau interaksi yang sedang dialami. Emosi juga berbentuk sesuatu yang spesifik seperti rasa senang, takut, marah dsb, juga berbeda dalam intensitasnya (Santrock, 2007). Emosi meliputi perubahan fisiologis yang spesifik, proses kognitif, ekspresi verbal dan non verbal serta kecenderungan untuk bersikap (Oatley \& Jenkins, 1996 dalam Prosen \& Vitulic, 2017).

Menurut Lewis (2002), emosi terdiri dari dua tipe. Pertama, emosi primer, misalnya terkejut, senang, marah, sedih, takut dan jijik. Emosi primer ini juga muncul pada hewan, dan pada manusia akan mulai muncul mulai dari 6 bulan pertama kehidupannya. Kedua, emosi yang disadari (self conscious emotion) yaitu empati, cemburu dan kebingungan (1,5-2 tahun); bangga, malu dan bersalah, yang muncul di usia 2,5 tahun. Emosi ini memerlukan kognisi, terutama kesadaran diri

Kompetensi emosional merujuk kepada kemampuan seseorang untuk mengekspresikan, memahami dan meregulasi emosinya (Denham, 1998 pada Bosacki \& Moore, 2004). Pada anak usia dini, kemampuan untuk memahami dan meregulasi perasaannya merupakan satu kunci kemajuan (Dennis, 2006). Anak yang mampu memahami emosinya akan lebih mampu untuk mengendalikan cara mengekspresikannya serta memiliki kepekaan terhadap perasaan orang lain (Garner \& Power, 1996 dalam Morris dkk., 2007). Menjadi peka terhadap lingkungan dan orang lain merupakan salah satu hal yang sangat penting bagi kehidupan anak ke depan karena dengan kemampuan ini anak dapat lebih mudah beradaptasi, terlibat lebih konstruktif dalam komunitas lingkungan, bekerjasama, dsb. Anak-anak yang memahami emosinya dapat belajar untuk mengekspresikan emosi dalam cara yang tepat. Anak-anak yang mampu mengekspresikan emosi secara tepat akan mengarah pada interaksi yang positif dan sukses dengan orang lain yang merupakan prediktor kesehatan secara psikososial (Denham dkk, 2003 dalam Prosen \& Vitulic, 2017), dan kompetensi emosional yang rendah sering diprediksi memiliki masalah perilaku dan 
kesulitan belajar (Izard dkk., 2001; Trentacosta \& Fine, 2010 dalam Christelle dkk., 2019).

Kemampuan anak prasekolah untuk mengekspresikan emosi secara tepat tidak terlepas dari faktor intrinsik dan ekstrinsik (Fox \& Calkins, 2003; Thompson, 2011 dalam Prosen \& Vitulic, 2017). Faktor-faktor intrinsik yang memengaruhi antara lain kematangan dari system saraf pusat, temperamen (Derrybery \& Rothbart, 1988 dalam Prosen \& Vitulic, 2017 ), kemampuan kognitif, perkembangan motorik dan bahasa (Kopp \& Neufeld, 2003 dalam Prosen \& Vitulic, 2017), sedangkan faktor-faktor ekstrinsik meliputi lingkungan pengasuhan, hubungan sebaya dan harapan sosial (Fox \& Calkins, 2003; Thompson, 2011; Thompson \& Meyer, 2009 dalam Prosen \& Vitulic, 2017).

Pada usia 4-5 tahun, anak-anak mulai menunjukkan peningkatan kemampuan merefleksikan emosinya dan perlahan mulai memahami bahwa suatu kejadian yang sama akan dapat menimbulkan emosi yang berbeda untuk orang yang berbeda. Anak-anak pada usia ini pun mulai sadar untuk mengatur emosi mereka dalam rangka memenuhi standar sosial (Bruce,Olen, \& Jensen, 1999 dalam Santrock, 2007). Kemampuan untuk memenuhi standar sosial ini dijelaskan melalui tahap perkembangan psikososial anak menurut Erikson yang berada pada tahap perkembangan Initiative Vs Guilt dimana anak memiliki keinginan untuk melakukan sesuatu terus menerus namun disisi lain mulai mengerti bahwa terkadang sesuatu yang ingin mereka lakukan perlu penerimaan dari orang lain (social approval) (Papalia, 2001).

Berdasarkan penelitian yang dilakukan oleh Bandura (1966), perilaku anak didasarkan pada apa yang mereka amati dari perilaku orang lain dan apa konsekuensi dari tindakan tersebut. Penelitian ini membuktikan bahwa respon-respon emosi juga dipelajari secara substitutif (Bandura \& Rosenthal, 1966; Berger, 1962; Craig \& Weinstein, 1965). Menurut Bandura (1986), pembelajaran lewat pengamatan dipengaruhi 4 variabel, yaitu: proses atensi, yang menentukan apa yang kita perhatikan; proses retensi, yang menentukan bagaimana pengalaman dikodekan di dalam memori; proses reproduksi-motorik, yang menentukan perilaku apa yang dapat dikerjakan; dan proses motivasi yang menentukan situasi apa pembelajaran diterjemahkan menjadi suatu performa tindakan sehingga dalam perkembangan emosinya, anak akan cenderung belajar dari banyak stimulasi yang diterima olehnya dalam 
keseharian. Anak akan belajar bagaimana mengekspresikan emosinya dari mengamati bagaimana orang disekitarnya bereaksi misalnya orangtua, saudara, guru, teman sepermainan, dsb. Dalam hal ini, anak akan belajar bagaimana memahami emosi diri dan orang lain dari pengalaman - pengalaman yang ditemuinya. Selain itu, anak akan belajar bagaimana cara mengelola emosi yang dirasakannya yang tidak lepas pengaruhnya dari orangtua, pengasuh dan lingkungan terdekatnya.

Perkembangan emosi anak prasekolah yang meliputi ekspresi dan regulasi emosi akan berkembang lebih baik dengan hal-hal yang dapat diamati olehnya, sehingga membutuhkan dukungan dan penguatan yang lebih dari lingkungan sosialnya. Menurut Saarni (2011) keterampilan emosi anak berkembang sejalan dengan perkembangan kognitifnya, sebagai contoh pemahaman anak terhadap emosi orang lain akan meningkat bersamaan dengan interaksinya untuk menyadari pengalaman emosi seseorang, dengan kemampuan seseorang untuk berempati serta dengan kapasitas untuk mengerti penyebab dari emosi dan konsekuensi perilaku mereka. Ketika anak-anak belajar tentang bagaimana dan mengapa orang bertindak, maka anak-anak mengembangkan kemampuan untuk menyimpulkan apa yang sedang terjadi untuk diri mereka sendiri secara emosional. Kompetensi emosi berkembang selama tahuntahun prasekolah dan membantu anak-anak prasekolah untuk berhasil dalam tugas-tugas perkembangan penting pada masa itu; mempertahankan keterlibatan emosional dan perilaku yang positif dalam lingkungan fisik dan sosial, menciptakan dan memelihara hubungan dengan anak-anak dan orang dewasa lainnya, dan berurusan dengan emosi dalam konteks kelompok yang menuntut mereka untuk duduk diam, mengikuti arahan dalam kelompok bermain (Howes, 1987; Parker \& Gottman, 1989 dalam Denham \& Bassett 2018).

Anak usia 4-5 tahun yang bersekolah di TK memiliki kesempatan yang lebih luas untuk belajar mengenai keterampilan emosi terutama untuk mengenali emosi mereka dimana mereka memiliki kesempatan yang lebih banyak untuk berbicara mengenai emosi yang dirasakan dan mengenali emosi yang dirasakan oleh teman-temannya, dari guru ketika berinteraksi di dalam kelas maupun ketika bermain di luar kelas. Menurut Trentacosta dan Crespo (2020) anak prasekolah belajar untuk mengidentifikasi dan mengekspresikan apa yang membuat mereka senang atau sedih, sering dalam konteks bermain. Anak-anak prasekolah membangun pemahaman mereka tentang penyebab emosi berdasarkan pengamatan dan interaksi mereka lainnya. 
TK " $X$ " Jatinangor merupakan TK berakreditasi B yang tidak memiliki kurikulum khusus untuk mengajarkan kompetensi emosi misalnya penamaan emosi-emosi, pengekspresian emosi, serta pemahaman emosi-emosi pada siswa. Untuk mengajarkan kompetensi emosi pada siswa, guru menyelipkan pembelajaran mengenai kompetensi emosi, misalnya bertanya bagaimana perasaan anak-anak ketika pelajaran selesai yang biasanya dijawab "senang" atau "sulit" oleh anak-anak dan guru biasanya akan menanyakan kembali bagian mana yang membuat senang dan bagian mana yang membuat sulit dalam waktu yang singkat. Guru juga berusaha membantu anak mengelola emosi ketika merasa marah dan menangis berteriak pada saat kesulitan mengerjakan tugasnya.

Menurut Papalia (2001), anak-anak pada usia 4-5 tahun mulai mampu memahami emosi mereka namun mereka masih perlu banyak belajar terutama tentang penghayatan emosi, penamaan emosi yang dirasakan, bagaimana mengekspresikan emosi diri sendiri dan juga orang orang lain. Kemampuan mereka untuk mengembangkan emosi ini akan sangat membantu mereka dalam kehidupan sosialnya kelak. Sehingga, perlunya pendampingan dari guru ataupun orang tua mengenai pembelajaran emosi bagi anak usia prasekolah agar mereka mencapai keterampilan emosi yang dapat bermanfaat bagi kehidupan mereka kelak.

Penelitian ini bertujuan untuk memberikan gambaran kemampuan anak prasekolah mengekspresikan emosi yang terdiri dari aspek verbal berupa pengungkapan secara verbal mengenai apa yang dirasakan, aspek nonverbal yang dapat teramati berupa gesture dan ekspresi wajah serta pemahaman emosi berupa memberikan label mengenai emosi yang dirasakan oleh mereka serta hal-hal yang dapat memunculkan reaksi emosi tersebut.

\section{Metode}

Penelitian ini menggunakan metode kualitatif dengan pendekatan studi kasus karena peneliti ingin mendapatkan data secara terperinci dan mendalam yang melibatkan berbagai sumber informasi dari subjek. Penelitian studi kasus merupakan pendekatan kualitatif di mana peneliti mengeksplorasi kehidupan nyata, sistem terikat kontemporer (kasus) atau sistem terikat ganda (kasus), melalui pengumpulan data terperinci dan mendalam yang melibatkan berbagai sumber informasi (misalnya: 
observasi, wawancara, materi audiovisual, dan dokumen dan laporan) dan melaporkan deskripsi kasus serta tema kasus (Cresswell, 2018). Dalam kaitannya dengan penelitian ini, penulis ingin meneliti bagaimana gambaran ekpresi emosi pada anak usia prasekolah (usia 4-5 tahun) di TK " $\mathrm{X}$ " Jatinangor dimana TK " $\mathrm{X}$ " Jatinangor tidak memiliki kurikulum khusus untuk mengenalkan emosi pada siswa didiknya.

Subjek dalam penelitian kualitatif ini berjumlah 4 orang yang didapatkan dengan menggunakan purposive sampling dengan kriteria berusia 4-5 tahun, tidak memiliki hambatan dalam berbahasa dan hambatan dalam kognisi (berdasarkan penilaian guru) dan bersekolah di TK " $X$ " Jatinangor. Instrumen penelitian menggunakan wawancara semi struktur yang mengacu pada panduan wawancara yang dibuat oleh peneliti berdasarkan 2 tipe emosi yaitu emosi primer dan emosi yang disadari (Lewis, 2002 dalam Santrock 2007), dan peneliti tidak hanya menanyakan halhal yang ada pada panduan wawancara saja melainkan hal-hal lain mengikuti respon yang diberikan oleh subjek untuk mendapatkan data yang lebih mendalam. Panduan wawancara dalam bentuk pertanyaan terbuka (open ended question) dimana subjek penelitian dimungkinkan untuk menjawab secara bebas. Penelitian ini juga menggunakan observasi untuk melihat secara langsung bagaimana subjek mengekspresikan emosinya dalam keseharian ketika berada di sekolah.

Teknik analisis data yang digunakan dalam penelitian ini menggunakan analisis tematik sebagaimana dikemukakan oleh Braun \& Clarke (2006) Analisis tematik ini mengembangkan pendekatan yang dapat diakses dan fleksibel secara teoritis untuk menganalisis data kualitatif. Analisis tematik terdiri dari 6 fase yaitu (1) membiasakan diri dengan data yaitu membaca kembali data serta mencatat ide awal (2) menghasilkan kode awal yaitu pengkodean fitur data yang menarik secara sistematis di seluruh kumpulan data serta menyusun data yang relevan dengan setiap kode (3) mencari tema yaitu menyusun kode menjadi tema potensial, mengumpulkan semua data yang relevan dengan setiap tema potensial (4) meninjau tema yaitu memeriksa apakah tema berfungsi dalam kaitannya dengan ekstrak kode (level 1) dan seluruh kumpulan data (level 2), serta menghasilkan "peta" analisis tematik (5) menentukan dan menamai tema 
yaitu analisis yang sedang berlangsung untuk memperbaiki spesifikasi setiap tema dan keseluruhan cerita yang diceritakan analisis tersebut, menghasilkan definisi dan nama yang jelas untuk setiap tema (6)memproduksi laporan yaitu pemilihan contoh ekstrak yang jelas dan menarik, analisis akhir dari ekstrak yang dipilih, yang menghubungkan kembali analisis dengan pertanyaan penelitian dan literatur, menghasilkan laporan analisis ilmiah.

Data mengenai gambaran ekspresi emosi anak didapatkan melalui observasi dan wawancara terhadap anak sebagai data primer ketika pelajaran berlangsung selama di sekolah dan wawancara terhadap orang tua sebagai data sekunder dengan memberikan pertanyaan-pertanyaan terkait emosi primer (terkejut, senang, marah, sedih, takut dan jijik) serta emosi yang disadari (empati, cemburu, kebingungan, bangga, malu, dan bersalah) yaitu bagaimana anak mengekspresikan emosinya?; apa saja yang membuat anak merasakan emosinya?; bagaimana reaksi orang tua ketika anak mengekspresikan emosinya?

Data mengenai pemahaman emosi anak yang terdiri dari memberi label emosi didapatkan melalui kartu-kartu emosi primer (terkejut, senang, marah, sedih, takut, jjijik) dan emosi yang disadari (empati, cemburu, kebingungan, bangga, malu dan bersalah) dimana anak diminta untuk memberi label emosi pada kartu-kartu tersebut. Peneliti juga melakukan wawancara mengenai hal-hal apa saja yang dapat membuat mereka merasakan emosi-emosi yang tampak pada kartu dengan pertanyaan yaitu apa yang dirasakan oleh anak pada kartu ini?; apa nama emosi yang sesuai?; apakah kamu pernah merasakan hal yang sama?; apa yang membuat kamu merasakan emosi tersebut

Data mengenai lingkungan sekolah didapatkan melalui wawancara terhadap guru sebagai data sekunder dengan pertanyaan yaitu bagaimana sekolah memfasilitasi keterampilan emosi anak?; apa saja yang dilakukan oleh guru untuk mengajarkan keterampilan emosi anak selama di kelas?

H a s i 1 
Berdasarkan data yang dikumpulkan baik dari data primer maupun data sekunder dari semua subjek penelitian $(\mathrm{Z}, \mathrm{M}, \mathrm{I}, \mathrm{S})$ diketemukan gambaran tentang dua tema kompetensi emosi mereka, yakni ekspresi emosi (yang ditampilkan secara verbal dan non-verbal) serta pemahaman emosi (berupa memberikan label terhadap emosi serta hal-hal apa saja yang dapat memunculkan reaksi emosi yang dirasakan)

\section{Ekspresi Emosi}

Pada penelitian ini didapatkan gambaran mengenai ekspresi emosi dari ke-empat subjek pada tabel 1.1 dan 1.2 sebagai berikut.

Tabel 1.1 Ekspresi Emosi Primer

\begin{tabular}{|c|c|c|c|c|}
\hline $\begin{array}{c}\text { Emosi } \\
\text { Primer }\end{array}$ & Subjek $1(\mathrm{Z})$ & Subjek 2 (M) & Subjek 3 (I) & $4(S)$ \\
\hline & $\begin{array}{l}\text { Secara non- } \\
\text { verbal dan verbal } \\
\text { dengan } \\
\text { meletakkan } \\
\text { tangan di sambil } \\
\text { dadanya saget!", } \\
\text { mengucapkan } \\
\text { secara verbal } \\
\text { "duh ka ketika dan } \\
\text { mendengar suara } \\
\text { yang keras dan } \\
\text { tiba-tiba seperti } \\
\text { petasan dan petir }\end{array}$ & $\begin{array}{l}\text { Secara non } \\
\text { dan } \\
\text { meletakkan tangan } \\
\text { di dada sambil } \\
\text { membelalakkan } \\
\text { matanya dan } \\
\text { mengatakan "kaget } \\
\text { woy!" misalnya } \\
\text { ketika } \\
\text { punggungnya } \\
\text { ditepuk } \\
\text { temannya } \\
\text { belakang. dari }\end{array}$ & $\begin{array}{l}\text { Secara non- verbal } \\
\text { dengan menangis } \\
\text { dan mencari ibunya } \\
\text { ketika mendengar } \\
\text { suara yang keras dan } \\
\text { tiba-tiba seperti petir } \\
\text { dan petasan }\end{array}$ & $\begin{array}{l}\text { Secara non- } \\
\text { verbal dengan } \\
\text { berteriak dengan } \\
\text { kencang } \\
\text { misalnya ketika } \\
\text { terkejut melihat } \\
\text { cicak pada jarak } \\
\text { yang dekat. }\end{array}$ \\
\hline Senang & $\begin{array}{l}\text { secara nonverbal } \\
\text { dengan mimic } \\
\text { wajah tersenyum } \\
\text { lebar, ataupun } \\
\text { secara verbal } \\
\text { dengan } \\
\text { mengatakan "aku } \\
\text { seneng main ini" } \\
\text { pada saat ia }\end{array}$ & 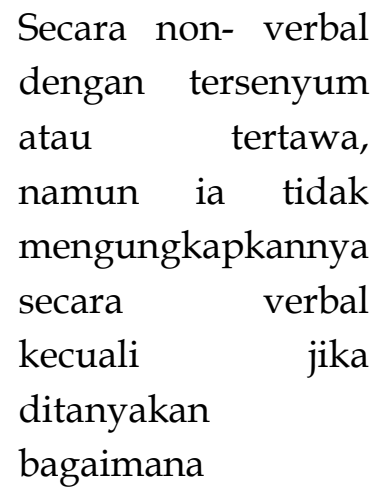 & 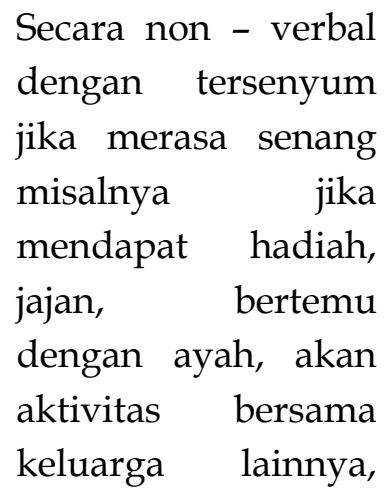 & $\begin{array}{l}\text { Secara non- } \\
\text { verbal dan verbal } \\
\text { dengan } \\
\text { tersenyum dan } \\
\text { mengatakan "aku } \\
\text { seneng sama } \\
\text { bonekanya" ketika } \\
\text { dibelikan mainan } \\
\text { kesukaannya, }\end{array}$ \\
\hline
\end{tabular}




\begin{tabular}{|c|c|c|c|c|}
\hline & $\begin{array}{l}\text { bermain mobil- } \\
\text { mobilan dengan } \\
\text { temannya }\end{array}$ & erasaannya & $\begin{array}{l}\text { namun tidak } \\
\text { mengekspresikannya } \\
\text { secara verbal kecuali } \\
\text { jika ditanyakan } \\
\text { bagaimana } \\
\text { perasaannya }\end{array}$ & $\begin{array}{l}\text { atau mengatakan } \\
\text { "seneng bangeeet" } \\
\text { melakukan } \\
\text { kegiatan yang } \\
\text { disukai seperti } \\
\text { menggambar, } \\
\text { main bola dan } \\
\text { seluncuran. }\end{array}$ \\
\hline Mara & $\begin{array}{l}\text { mengungkapkan } \\
\text { secara non- } \\
\text { verbal berupa } \\
\text { mimik wajah } \\
\text { yang marah } \\
\text { (bibir } \\
\text { melengkung ke } \\
\text { bawah) dan } \\
\text { secara verbal } \\
\text { "kenapa sih aku ga } \\
\text { diajak" atau } \\
\text { mengatakan } \\
\text { "kemana sih } \\
\text { mainan mobil } \\
\text { hotwheel aku" }\end{array}$ & $\begin{array}{lr}\text { Secara } & \text { non- } \\
\text { dengan merbal } & \text { mangis } \\
\text { dan melemparkan } \\
\text { barang } & \text { yang } \\
\text { didekatnya } & \text { jika } \\
\text { merasa } & \text { marah, } \\
\text { bahkan } & \text { tantrum } \\
\text { ketika } & \text { tidak } \\
\text { mendapatkan apa } & \text { apa } \\
\text { yang diinginkannya. }\end{array}$ & $\begin{array}{l}\text { secara non verbal } \\
\text { dengan menutup } \\
\text { pintu kamar dan } \\
\text { tidak mau berbicara } \\
\text { dengan siapapun, } \\
\text { bahkan melempar } \\
\text { barang karena } \\
\text { memperebutkan } \\
\text { barang tersebut } \\
\text { dengan kakaknya. }\end{array}$ & 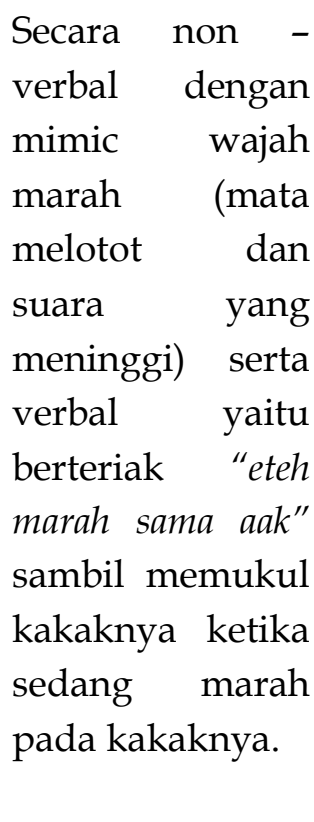 \\
\hline St & $\begin{array}{l}\text { berperilaku lebih } \\
\text { diam dan kurang } \\
\text { aktif seperti } \\
\text { biasanya dan } \\
\text { tidak } \\
\text { mengekspresikan } \\
\text { secara verbal } \\
\text { kecuali ditanya }\end{array}$ & $\begin{array}{l}\text { menangis jika } \\
\text { merasa sedih, } \\
\text { namun tidak } \\
\text { mengungkapkan } \\
\text { secara verbal bahwa } \\
\text { ia sedih meskipun } \\
\text { jika ditanya }\end{array}$ & $\begin{array}{l}\text { diam lalu menangis } \\
\text { dan akan } \\
\text { menceritakan } \\
\text { penyebab dirinya } \\
\text { menangis ketika } \\
\text { ditanya oleh ibunya }\end{array}$ & $\begin{array}{l}\text { akan } \\
\text { mengekspresikan } \\
\text { sedihnya dengan } \\
\text { cara menangis, } \\
\text { memeluk ibu } \\
\text { dan } \\
\text { mengungkapkan } \\
\text { dengan } \\
\text { mengatakan } \\
\text { "mama, aku } \\
\text { sedih..." }\end{array}$ \\
\hline Takut & \begin{tabular}{l}
\multicolumn{2}{l}{ Bersembunyi } \\
misalnya ketika \\
merasa takut \\
dengan bunyi \\
petir dan \\
mengatakan "ih, \\
takut...".
\end{tabular} & $\begin{array}{l}\text { Menangis ketika } \\
\text { merasa takut dan } \\
\text { tidak } \\
\text { mengekspresikan } \\
\text { secara verbal } \\
\text { tentang } \\
\text { perasaannya. }\end{array}$ & $\begin{array}{l}\text { Memeluk ibu jika } \\
\text { merasa } \\
\text { misalnya takut } \\
\text { terhadap takut } \\
\text { sambil mengatakan } \\
\text { "bu, takut bu...". }\end{array}$ & $\begin{array}{l}\text { Tidak pernah } \\
\text { menunjukkan } \\
\text { rasa takutnya }\end{array}$ \\
\hline
\end{tabular}




\begin{tabular}{|c|c|c|c|c|}
\hline & $\begin{array}{l}\text { Secara verbal } \\
\text { "aku ga mau ah, } \\
\text { jijik...." dengan } \\
\text { ekspresi wajah } \\
\text { mengernyitkan } \\
\text { dahi } \\
\text { memperlihatkan } \\
\text { ia jijik ketika } \\
\text { ditawarkan } \\
\text { minum } \\
\text { menggunakan } \\
\text { gelas bekas adik } \\
\text { atau sendok } \\
\text { bekas orang lain }\end{array}$ & $\begin{array}{l}\text { Secara non-verbal } \\
\text { dengan } \\
\text { mengeluarkan } \\
\text { lidahnya ketika } \\
\text { melihat kotoran }\end{array}$ & $\begin{array}{l}\text { Mudah merasa jijik } \\
\text { dengan benda-benda } \\
\text { yang lengket seperti } \\
\text { lem karena tidak } \\
\text { dibiasakan di rumah, } \\
\text { ketika menghadapi } \\
\text { lem, ia biasanya } \\
\text { akan memegangnya } \\
\text { secara perlahan } \\
\text { dengan ujung jari } \\
\text { dengan mimik wajah } \\
\text { yang menunjukkan } \\
\text { ia jijik }\end{array}$ & $\begin{array}{l}\text { Merasa jijik } \\
\text { ketika melihat } \\
\text { kotoran cicak, ia } \\
\text { akan berteriak } \\
\text { dan mengatakan } \\
\text { pada ibu nya "ih, } \\
\text { geuleuh" (ih, jijik). } \\
\text { Ia juga merasa } \\
\text { jijik jika } \\
\text { mencium bau } \\
\text { yang tidak enak } \\
\text { dan merasa mual } \\
\text { sambil mengatakan } \\
\text { "geuleuh"(jijik). }\end{array}$ \\
\hline
\end{tabular}

Berdasarkan tabel 1.1 subjek Z mampu mengekspresikan emosi secara verbal dan nonverbal pada emosi terkejut, senang, marah, takut, jijik, dan mengekspresikan secara non-verbal saja pada emosi sedih. Subjek M mampu mengekspresikan emosi secara verbal dan non-verbal pada emosi terkejut, sedangkan empat emosi lainnya yaitu senang, marah, sedih, takut dan jijik diekspresikan secara non-verbal. Subjek I mampu mengekspresikan emosi secara verbal dan non-verbal hanya pada emosi takut, sedangkan pada emosi terkejut, senang, marah, sedih dan jijik diekspresikan secara non-verbal. Subjek S mampu mengekspresikan emosi secara verbal dan non-verbal pada emosi senang, marah, sedih, jijik, sedangkan pada emosi jijik diekspresikan secara non-verbal. Subjek $S$ belum terlihat mengekspresikan emosi takut.

Gambaran ekspresi emosi pada emosi yang disadari (Self Conscious Emotion) tertera pada tabel sebagai berikut.

Tabel 1.2 Ekspresi Emosi Yang Disadari

\begin{tabular}{|c|c|c|c|c|}
\hline $\begin{array}{c}\text { Emosi } \\
\text { Yang } \\
\text { Disadari }\end{array}$ & Subjek $1(\mathrm{Z})$ & Subjek 2 (M) & Subjek 3 (I) & Subjek 4 (S) \\
\hline Cemburu & mengatakan & Mengatakan & secara & menempel ke ibu atau \\
\hline & $\begin{array}{l}\text { ih ngobrol wae, } \\
\text { temenin aku main" } \\
\text { sambil cemberut } \\
\text { ketika ibu sedang } \\
\text { asik berbicara }\end{array}$ & $\begin{array}{l}\text { "kenapa aa' yang } \\
\text { boleh main game } \\
\text { nya" ketika } \\
\text { kakaknya } \\
\text { diperbolehkan }\end{array}$ & $\begin{array}{l}\text { "koq, ibu ke aa' } \\
\text { terus sih" ketika } \\
\text { orang tua } \\
\text { mendahulukan } \\
\text { kakaknya }\end{array}$ & $\begin{array}{l}\text { menarik kerudung } \\
\text { ibu ketika ibu lebih } \\
\text { memperhatikan atau } \\
\text { menemani } \\
\text { bermain atau ketika }\end{array}$ \\
\hline
\end{tabular}




\begin{tabular}{|c|c|c|c|c|}
\hline & dengan temannya & $\begin{array}{l}\text { main game } \\
\text { terlebih dahulu, } \\
\text { sambil } \\
\text { memperlihatkan } \\
\text { mimik wajah } \\
\text { yang cemberut }\end{array}$ & $\begin{array}{l}\text { sambil } \\
\text { memperlihatkan } \\
\text { mimik wajah } \\
\text { yang cemberut }\end{array}$ & $\begin{array}{l}\text { ibu sibuk berbicara } \\
\text { dengan temannya dan } \\
\text { kurang } \\
\text { memperhatikannya }\end{array}$ \\
\hline Empati & $\begin{array}{l}\text { menawarkan } \\
\text { teman untuk } \\
\text { bermain } \\
\text { bersamanya } \\
\text { dengan } \\
\text { mengatakan "kamu } \\
\text { mau main ini ga?", }\end{array}$ & $\begin{array}{l}\text { belum terlihat } \\
\text { mengekspresikan } \\
\text { emosi empati }\end{array}$ & $\begin{array}{l}\text { menolong } \\
\text { teman yang } \\
\text { jatuh ketika } \\
\text { sedang bermain }\end{array}$ & \begin{tabular}{lr} 
Inisiatif & menyapu \\
lantai jika melihat \\
lantainya & kotor, \\
membantu & ibu \\
mencuci piring tanpa \\
diminta dan \\
berinisiatif membantu \\
ibu mencari ponsel \\
ketika ibu sedang \\
\multicolumn{2}{l}{ sibuk mencari ponsel. }
\end{tabular} \\
\hline $\mathrm{Bi}$ & $\begin{array}{l}\text { diam dan } \\
\text { memperhatikan } \\
\text { situasi sekitarnya, } \\
\text { ia mengatakan "ga } \\
\text { tau" ketika } \\
\text { ditanyakan apa } \\
\text { yang ia rasakan } \\
\text { misalnya pada } \\
\text { situasi di kelas } \\
\text { dimana ia melihat } \\
\text { temannya yang } \\
\text { sedang menangis }\end{array}$ & $\begin{array}{l}\text { tidak terlihat } \\
\text { mengekspresikan } \\
\text { emosi bingung. }\end{array}$ & $\begin{array}{l}\text { mengernyitkan } \\
\text { dahinya sambil } \\
\text { mengatakan } \\
\text { "aku ga ngerti } \\
\text { deh" ketika } \\
\text { mengerjakan } \\
\text { tugas yang } \\
\text { membuat ia } \\
\text { bingung }\end{array}$ & $\begin{array}{lr}\text { diam ketika merasa } \\
\text { bingung } & \text { dan } \\
\text { mengatakan "ga tau } \\
\text { ah, bingung" sambil } \\
\text { cemberut } & \text { dan } \\
\text { mengernyitkan dahi } \\
\text { ketika } \\
\text { bingung merasa } \\
\text { permainan barunya }\end{array}$ \\
\hline Bangga & $\begin{array}{l}\text { diam dan } \\
\text { tersenyum sambil } \\
\text { melihat ke arah } \\
\text { ibu ketika ia dipuji } \\
\text { karena berhasil } \\
\text { duduk tertib di } \\
\text { kelas. }\end{array}$ & $\begin{array}{l}\text { Tersenyum } \\
\text { sambil } \\
\text { mengatakan } \\
\text { "weeeh, liat weeeh } \\
\text { punya ku bagus } \\
\text { kata bu guru" } \\
\text { pada situasi ia } \\
\text { dipuji karena } \\
\text { mengerjakan } \\
\text { tugas dengan } \\
\text { baik. }\end{array}$ & $\begin{array}{l}\text { Tersenyum dan } \\
\text { diam ketika ia } \\
\text { dipuji karena } \\
\text { mendapatkan } \\
\text { nilai yang } \\
\text { paling baik di } \\
\text { kelasnya }\end{array}$ & $\begin{array}{l}\text { diam sambil } \\
\text { tersenyum misalnya } \\
\text { pada situasi ia dipuji } \\
\text { oleh guru karena } \\
\text { berhasil mengerjakan } \\
\text { seluruh tugasnya }\end{array}$ \\
\hline
\end{tabular}






Berdasarkan tabel 1.2 subjek Z mampu mengekspresikan emosi yang disadari secara verbal dan non-verbal pada emosi cemburu, empati, bingung, malu, marah, dan mengekspresikan secara non-verbal saja pada emosi bangga. Subjek $M$ mampu mengekspresikan emosi secara verbal dan non-verbal pada emosi cemburu, dan belum memperlihatkan ekspresi empati, bingung, bangga, malu, marah. Subjek I mampu mengekspresikan secara verbal dan non-verbal pada emosi cemburu, bingung, marah, serta mengekspresikan secara non-verbal saja pada emosi empati, bangga, malu. Subjek S mampu mengekspresikan secara verbal dan non-verbal pada emosi bingung, marah, sedangkan mengekspresikan secara non-verbal saja pada emosi cemburu, empati, bangga, malu.

\section{Pemahaman Emosi}

Pada tema pemahaman emosi yang terdiri dari kemampuan melabeli emosi dan mengetahui hal apa saja yang memunculkan emosi yang dirasakannya didapatkan hasil pada tabel 2.1 - 2.2 sebagai berikut. 
Tabel 2.1 Pemahaman Emosi Primer

\begin{tabular}{|c|c|c|c|c|}
\hline $\begin{array}{l}\text { Emosi } \\
\text { Primer }\end{array}$ & Subjek $1(\mathrm{Z})$ & Subjek 2 (M) & Sub & \\
\hline & $\begin{array}{l}\text { memberikan label } \\
\text { pada kartu } \\
\text { "kaget", ia juga } \\
\text { mengetahui } \\
\text { bahwa ia akan } \\
\text { mudah terkejut } \\
\text { jika mendengar } \\
\text { suara keras "kalo } \\
\text { denger suara } \\
\text { tembakan, kaget". }\end{array}$ & 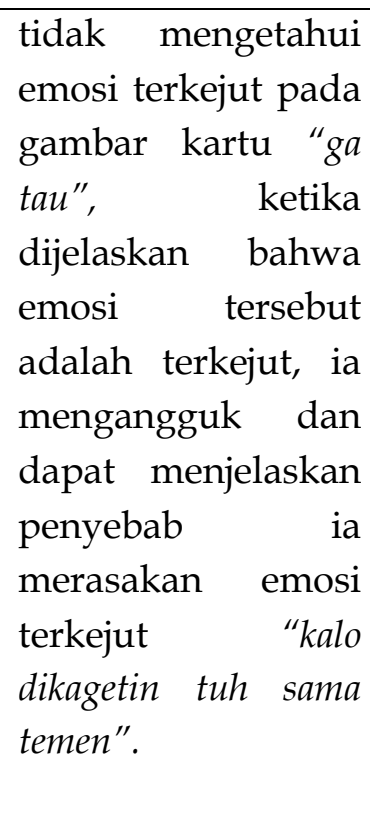 & $\begin{array}{l}\text { memberikan } \\
\text { label tepat pada } \\
\text { gambar"ini kaget } \\
\text { ya", ia juga dapat } \\
\text { menceritakan } \\
\text { kejadian yang } \\
\text { membuatnya } \\
\text { merasakan kaget } \\
\text { "kalo denger suara } \\
\text { keras kaya petir, } \\
\text { petasan gitu, trus } \\
\text { aku nangis deh". }\end{array}$ & $\begin{array}{l}\text { Belum dapat } \\
\text { memberikan label } \\
\text { emosi yang tepat. Ia } \\
\text { menyatakan apa } \\
\text { yang kira-kira } \\
\text { diucapkan oleh anak } \\
\text { pada gambar "ya } \\
\text { ampun", ketika } \\
\text { dijelaskan mengenai } \\
\text { emosi terkejut, ia } \\
\text { dapat menjelaskan } \\
\text { hal yang membuat } \\
\text { ia terkejut "liat cicak } \\
\text { kalo deket aku, aku } \\
\text { teriak".. }\end{array}$ \\
\hline & $\begin{array}{l}\text { memberikan label } \\
\text { padar kartu } \\
\text { "senyum, senang", } \\
\text { ia memahami } \\
\text { bahwa dirinya } \\
\text { akan merasa } \\
\text { senang jika } \\
\text { dibelikan mainan } \\
\text { mobil-mobilan } \\
\text { baru oleh ayahnya } \\
\text { "kalo aku seneng } \\
\text { kalo dibeliin mainan } \\
\text { mobil baru sama } \\
\text { ayah" }\end{array}$ & $\begin{array}{l}\text { memberikan label } \\
\text { "senang", ia dapat } \\
\text { menjelaskan hal } \\
\text { yang menyebabkan } \\
\text { ia merasa senang } \\
\text { yaitu "senang kalo } \\
\text { dikasih main game di } \\
\text { HP", }\end{array}$ & $\begin{array}{l}\text { Dapat } \\
\text { memberikan } \\
\text { label dengan } \\
\text { tepat "tertawa, } \\
\text { senang", ia } \\
\text { mengungkapkan } \\
\text { hal yang } \\
\text { membuat ia } \\
\text { senang "senang } \\
\text { kalau diajak jalan- } \\
\text { jalan ke tempat } \\
\text { permainan gitu". }\end{array}$ & $\begin{array}{l}\text { memberikan label } \\
\text { ekspresi anak pada } \\
\text { gambar"senyum, ga } \\
\text { tau", ketika } \\
\text { dijelaskan emosi } \\
\text { senang, ia dapat } \\
\text { menjelaskan hal } \\
\text { yang membuat ia } \\
\text { senang "kalo dibeliin } \\
\text { boneka sama ayah". }\end{array}$ \\
\hline $\mathrm{M}$ & $\begin{array}{l}\text { memberi label } \\
\text { pada kartu } \\
\text { "marah" dan } \\
\text { menyatakan "kalo } \\
\text { aku ga pernah } \\
\text { marah-marah". }\end{array}$ & $\begin{array}{l}\text { memberikan label } \\
\text { "marah", ia dapat } \\
\text { menjelaskan hal } \\
\text { yang menyebabkan } \\
\text { ia merasakan emosi } \\
\text { marah "aku marah } \\
\text { kalo lagi main game } \\
\text { diganggu kakak" }\end{array}$ & $\begin{array}{l}\text { memberikan } \\
\text { label tepat } \\
\text { "marah", ra } \\
\text { menyatakan } \\
\text { kejadian yang } \\
\text { membuat } \\
\text { merasakan } \\
\text { marah } \\
\end{array}$ & $\begin{array}{lr}\text { belum dapat } & \text { memberikan label } \\
\text { yang tepat "ga tau", } \\
\text { ketika dijelaskan } \\
\text { mengenai emosi } \\
\text { marah, ia dapat } \\
\text { menjelaskan yang } \\
\text { membuat ia marah }\end{array}$ \\
\hline
\end{tabular}




\begin{tabular}{|c|c|c|c|c|}
\hline & & & $\begin{array}{l}\text { rebutan mainan } \\
\text { dengan kakak" }\end{array}$ & $\begin{array}{l}\text { "kalo lagi rebutan } \\
\text { mainan sama kakak". }\end{array}$ \\
\hline St & 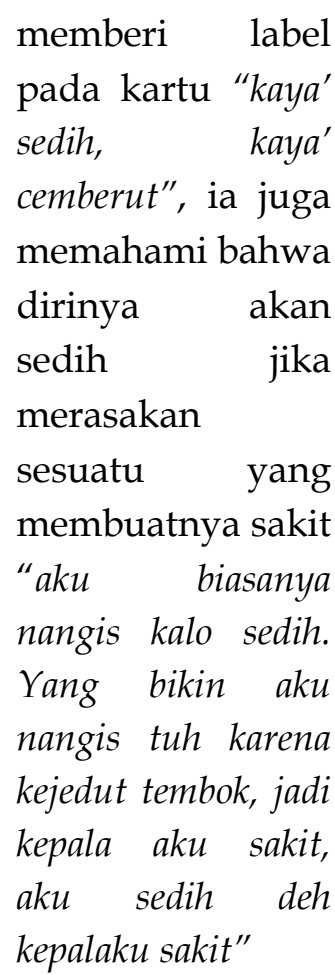 & $\begin{array}{lr}\text { belum } & \text { dapat } \\
\text { memberikan label } \\
\text { tepat, namun dapat } \\
\text { menyebutkan apa } \\
\text { yang terjadi dengan } \\
\text { gambar di kartu } \\
\text { "nangis", ia dapat } \\
\text { menjelaskan } \\
\text { mengapa } \\
\text { menangis ia } \\
\text { nangis "aku } \\
\text { digangguin kakak", } \\
\text { ketika dijelaskan } \\
\text { mengenai } \\
\text { sedih, ia dapat } \\
\text { menjelaskan "aku } \\
\text { sedih kalo dimarahin } \\
\text { ummi" }\end{array}$ & $\begin{array}{l}\text { dapat } \\
\text { memberikan } \\
\text { label yang tepat } \\
\text { "sedih, dia } \\
\text { nangis", ia } \\
\text { menceritakan } \\
\text { yang membuat ia } \\
\text { sedih "kalo ayah } \\
\text { ga pulang padahal } \\
\text { udah janji" }\end{array}$ & 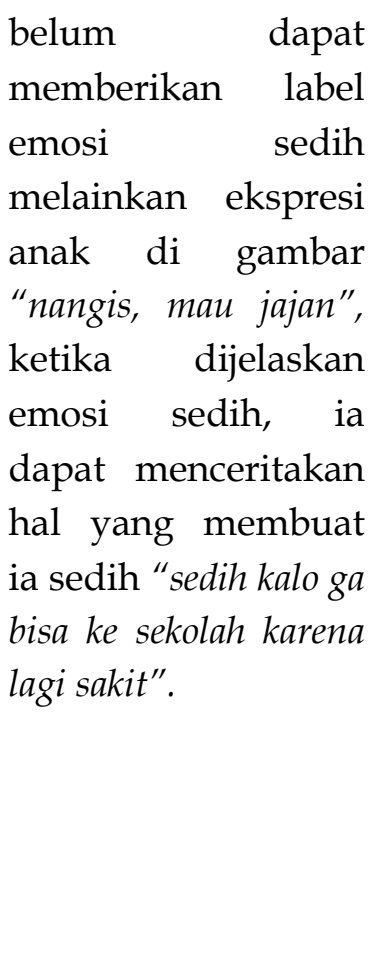 \\
\hline Takı & $\begin{array}{l}\text { Belum dapat } \\
\text { memberi label } \\
\text { emosi takut pada } \\
\text { gambar, } \\
\text { melainkan ia } \\
\text { menjelaskannya } \\
\text { "kaya' sedih, kaya' } \\
\text { cemberut". Setelah } \\
\text { dijelaskan } \\
\text { mengenai emosi } \\
\text { takut, ia } \\
\text { menyatakan "aku } \\
\text { takut kalo denger } \\
\text { suara petir lagi } \\
\text { sendirian di kamar" }\end{array}$ & $\begin{array}{lr}\text { belum } & \text { dapat } \\
\text { memberikan label } \\
\text { pada emosi } & \text { takut } \\
\text { "ga tau", ketika } \\
\text { dijelaskan emosi } \\
\text { takut, ia dapat } \\
\text { menceritakan apa } \\
\text { saja yang membuat } \\
\text { ia takut "takut } \\
\text { hantu, serem". }\end{array}$ & $\begin{array}{l}\text { memberikan } \\
\text { label yang tepat } \\
\text { "takut", ia } \\
\text { menceritakan } \\
\text { "aku takut sama } \\
\text { ular, sama hantu, } \\
\text { sama anjing juga, } \\
\text { galak". }\end{array}$ & $\begin{array}{l}\text { belum dapat } \\
\text { memberikan label } \\
\text { yang tepat pada } \\
\text { emosi takut "ga tau, } \\
\text { lagi apa itu?", ketika } \\
\text { dijelaskan mengenai } \\
\text { emosi takut, ia } \\
\text { menyatakan bahwa } \\
\text { ia tidak merasakan } \\
\text { takut "ga pernah } \\
\text { takut, soalnya selalu } \\
\text { sama mamakan". }\end{array}$ \\
\hline Jijik & $\begin{array}{l}\text { Mampu } \\
\text { memberikan label } \\
\text { dengan tepat } \\
\text { "buka lidah, merasa } \\
\text { meniijikkan". Ia }\end{array}$ & $\begin{array}{lr}\text { belum } & \text { dapat } \\
\text { memberikan label } & \text { emosi jijik "ada yang } \\
\text { ga enak", } & \text { ketika } \\
\text { dijelaskan emosi }\end{array}$ & $\begin{array}{l}\text { memberikan } \\
\text { label yang tepat } \\
\text { pada emosi jjik } \\
\text { "ini julurin lidah, } \\
\text { karena jijik", ia }\end{array}$ & $\begin{array}{lr}\text { belum } & \text { dapat } \\
\text { memberikan } & \text { label } \\
\text { emosi } & \text { jijik } \\
\text { "bercanda", } & \text { ketika } \\
\text { dijelaskan mengenai }\end{array}$ \\
\hline
\end{tabular}




$\begin{array}{llrlr}\text { juga memahami } & \text { jijik, ia dapat } & \text { menceritakan } & \text { emosi jjik, ia dapat } \\ \text { yang } & & \text { menceritakan "jijik } & \text { kejadian yang } & \text { menceritakan bahwa } \\ \text { menyebabkan ia kalo liat kotoran, membuat ia jijik ia merasa jjik } & \text { ia "jijik sama yang dengan kotoran } \\ \text { jijik "kalo aku jijik hiiiy". } & & \begin{array}{l}\text { lengket kaya'lem". cicak "sama ee'nya } \\ \text { pada sampah" }\end{array} & & \text { cicak, ih geuleuuh". } \\ & & & \end{array}$

Berdasarkan tabel 2.1 semua subjek mampu menjelaskan hal-hal apa saja yang membuat mereka merasakan emosi-emosi primer, namun tidak semua mampu memberikan label yang tepat pada emosi-emosi primer. Subjek Z mampu memberikan label yang tepat pada hampir semua emosi primer (5 dari 6 emosi) dan blum mampu memberikan memberikan label yang tepat pada satu emosi yaitu emosi takut, namun ia memahami hal apa saja yang membuat ia merasakan seluruh emosiprimer tersebut. Subjek M mampu memberikan label yang tepat pada dua emosi primer, ketika dijelaskan mengenai emosi-emosi tersebut, ia dapat memberikan contoh hal apa saja yang membuat ia merasakan emosi-emosi yang dimaksud. Subjek I dapat memberikan label yang tepat pada seluruh emosi primer dan menjelaskan hal-hal apa saja yang dapat membuat ia merasakan emosi-emosi tersebut. Subjek $S$ baru mampu memberikan label yang tepat pada satu emosi, namun ia masih mampu memberikan contoh hal apa saja yang membuat ia merasakan emosi-emosi primer tersebut.

Gambaran pemahaman emosi yang disadari (Self Conscious Emotion) digambarkan pada pada tabel berikut ini.

Tabel 2.2. Pemahaman Emosi Yang Disadari

\begin{tabular}{|c|c|c|c|c|}
\hline $\begin{array}{c}\text { Emosi } \\
\text { Yang } \\
\text { Disadari }\end{array}$ & Subjek 1 (Z) & Subjek 2 (M) & Subjek 3 (I) & Subjek 4 (S) \\
\hline Cemburu & $\begin{array}{l}\text { mampu } \\
\text { menceritakan dan } \\
\text { mengungkapkan } \\
\text { perasaan anak pada } \\
\text { kartu, namun } \\
\text { belum dapat } \\
\text { memberikan label } \\
\text { emosi cemburu. Ia } \\
\text { menyatakan "ini }\end{array}$ & $\begin{array}{l}\text { mampu } \\
\text { menceritakan } \\
\text { perasaan anak pada } \\
\text { kartu, namun } \\
\text { belum dapat } \\
\text { memberikan label } \\
\text { emosi cemburu. Ia } \\
\text { menyatakan "ini } \\
\text { lagi kesel" ia dapat }\end{array}$ & $\begin{array}{l}\text { belum dapat } \\
\text { memberikan } \\
\text { label yang tepat } \\
\text { melainkan } \\
\text { menjelaskan } \\
\text { kejadian pada } \\
\text { gambar "ini dia } \\
\text { lagi kesel ya, } \\
\text { mama papa nya }\end{array}$ & 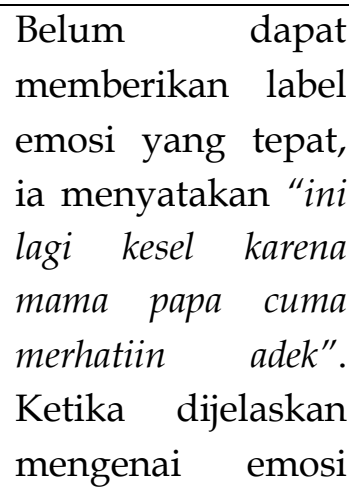 \\
\hline
\end{tabular}




\begin{tabular}{|c|c|c|c|c|}
\hline & $\begin{array}{l}\text { marah ya?" ia dapat } \\
\text { menceritakan } \\
\text { kejadian pada kartu } \\
\text { "soalnya ayah ibunya } \\
\text { main sama adiknya } \\
\text { aja". ia juga dapat } \\
\text { menjelaskan emosi } \\
\text { yang ia rasakan } \\
\text { ketika mengalami } \\
\text { hal yang sama "kalo } \\
\text { aku ga marah sih, } \\
\text { soalnya adekku kan } \\
\text { lebih kecil jadi ga apa } \\
\text { apa". }\end{array}$ & $\begin{array}{l}\text { menceritakan } \\
\text { kejadian pada kartu } \\
\text { "ummi sama abbinya } \\
\text { lagi sama adeknya", } \\
\text { ia dapat } \\
\text { menjelaskan emosi } \\
\text { yang ia rasakan } \\
\text { ketika mengalami } \\
\text { hal yang sama "kalo } \\
\text { aku juga kesel kalo } \\
\text { ummi sama abi lagi } \\
\text { ngobrol aja sama aa' } \\
\text { ". }\end{array}$ & $\begin{array}{l}\text { lagi sama } \\
\text { adeknya", ketika } \\
\text { dijelaskan } \\
\text { mengenai emosi } \\
\text { cemburu, ia } \\
\text { dapat } \\
\text { menjelaskan hal } \\
\text { yang membuat } \\
\text { ia merasa } \\
\text { cemburu "oh, } \\
\text { kalo mama lagi } \\
\text { ngobrol wae sama } \\
\text { temennya, } \\
\text { padahal aku juga } \\
\text { mau ngomong". }\end{array}$ & $\begin{array}{l}\text { cemburu, ia dapat } \\
\text { menceritakan hal } \\
\text { yang membuat ia } \\
\text { merasakan emosi } \\
\text { cemburu } \\
\text { "mmm...aku juga } \\
\text { gitu kalo mama suka } \\
\text { ngobrol aja sama } \\
\text { kakak" }\end{array}$ \\
\hline & $\begin{array}{l}\text { Belum dapat } \\
\text { memberikan label } \\
\text { emosi yang tepat } \\
\text { "jatuh, trus } \\
\text { temennya bantuin", } \\
\text { ia dapat } \\
\text { menjelaskan } \\
\text { mengapa anak pada } \\
\text { gambar di kartu } \\
\text { membantu } \\
\text { temannya } \\
\text { "temennya bantuin } \\
\text { karena kasihan", ia } \\
\text { juga dapat } \\
\text { memahami bahwa } \\
\text { ia akan melakukan } \\
\text { hal yang sama jika } \\
\text { mengalami } \\
\text { kejadian yang sama } \\
\text { "kalo aku juga aku } \\
\text { bantuin". }\end{array}$ & $\begin{array}{l}\text { Belum dapat } \\
\text { memberikan label } \\
\text { yang tepat. } \\
\text { Menyatakan "lagi } \\
\text { maen, trus jatuh, } \\
\text { trus temennya } \\
\text { bantuin", ia tidak } \\
\text { dapat menjelaskan } \\
\text { mengapa anak } \\
\text { pada gambar di } \\
\text { kartu membantu } \\
\text { temannya "ya } \\
\text { karena temennya } \\
\text { jatuh jadi ya } \\
\text { bantuin". Ia dapat } \\
\text { memahami bahwa } \\
\text { ia akan melakukan } \\
\text { hal yang sama jika } \\
\text { mengalami kejadian yang sama } \\
\text { "kalo jatuh di deket } \\
\text { aku, aku bantuin". }\end{array}$ & $\begin{array}{l}\text { belum dapat } \\
\text { memberikan } \\
\text { label tepat "ini } \\
\text { nolongin } \\
\text { temennya yang } \\
\text { jatuh", ia dapat } \\
\text { menjelaskan apa } \\
\text { yang dirasakan } \\
\text { ketika melihat } \\
\text { teman yang } \\
\text { terjatuh "kasian } \\
\text { atuh, jadi dibantu } \\
\text { deh". }\end{array}$ & $\begin{array}{l}\text { Belum dapat } \\
\text { memberikan label } \\
\text { emosi yang tepat } \\
\text { "ini tuh temennya } \\
\text { jatuh, trus dia } \\
\text { bantuin" . Ia } \\
\text { memahami bahwa } \\
\text { ia akan melakukan } \\
\text { hal yang sama jika } \\
\text { mengalami } \\
\text { kejadian serupa } \\
\text { "kalo aku juga } \\
\text { bantuin" }\end{array}$ \\
\hline Bingun & $\begin{array}{l}\text { memberikan label } \\
\text { tepat "ini apa ya, dia } \\
\text { ga ngerti kayanya ya? } \\
\text { Bingung ya?", ia }\end{array}$ & $\begin{array}{l}\text { belum dapat } \\
\text { memberikan label } \\
\text { tepat "ini ga tau", } \\
\text { ketika dijelaskan }\end{array}$ & $\begin{array}{l}\text { mengatakan } \\
\text { "bingung ya", ia } \\
\text { menceritakan } \\
\text { bahwa ia }\end{array}$ & $\begin{array}{l}\text { Memberikan label } \\
\text { yang tepat "dia ga } \\
\text { ngerti, bingung". Ia } \\
\text { juga dapat }\end{array}$ \\
\hline
\end{tabular}











Berdasarkan tabel 2.2 yaitu pada emosi yang disadari, Subjek Z baru mampu memberikan label yang tepat pada emosi bingung dan malu, ia mampu menjelaskan hal-hal apa saja yang menyebabkan ia merasakan seluruh emosi-emosi yang disadari . Subjek M belum dapat memberikan label yang tepat pada emosi-emosi yang disadari, namun masih mampu untuk menjelaskan hal-ahal apa saja yang menyebabkan ia merasakan seluruh emosi-emosi yang disadari. Subjek I mampu memberikan label yang tepat pada emosi kebingungan, bangga dan malu, ia juga mampu menjelaskan hal-hal apa saja yang menyebabkan ia merasakan seluruh emosi-emosi yang disadari. Subjek S mampu memberikan label yang tepat pada emosi bingung dan malu, ia juga mampu menjelaskan menjelaskan hal-hal apa saja yang menyebabkan ia merasakan seluruh emosi-emosi yang disadari.

\section{Pembahasan}

\section{Ekspresi Emosi}

Ekspresi emosi termasuk pengalaman emosi diri sendiri dan pengiriman pesan emosional kepada orang lain adalah inti dari kompetensi emosi. Emosi mestinya diekspresikan sesuai dengan tujuan dan konteks sosial, oleh karenanya anak perlu mengoordinasikan tujuan dirinya dan orang lainnya, mengalami dan mengekspresikan 
emosi dengan cara yang menguntungkan untuk interaksi dari momen ke momen serta hubungan sepanjang waktu (Halberstadt dkk., 2001 dalam Denham, 2019).

Pada penelitian ini, setiap subjek memiliki kemampuan yang berbeda dalam mengekspresikan setiap jenis emosi. Hampir semua subjek (3 dari 4) mampu mengekspresikan emosi- emosi primer secara non-verbal (melalui mimik wajah dan gesture) dengan tepat, hanya saja tidak semua mampu mengekspresikannya secara verbal (mengungkapkan apa yang ia rasakan). Subjek Z dan S mengekspresikan lebih banyak emosi primer baik secara verbal dan non-verbal, sedangkan pada subjek $\mathrm{M}$ dan I memiliki kemampuan mengekspresikan emosi primer secara verbal yang masih terbatas.

Pada emosi yang disadari, diketahui bahwa seluruh subjek juga telah mengembangkan kemampuannya untuk mengekspresikan emosi yang disadari khususnya secara non-verbal. Pada kemampuan mengekspresikan secara verbal dan non-verbal, Subjek Z mampu mengekspresikan lima emosi (cemburu, empati, bingung, malu, marah), subjek I mampu mengekspresikan tiga emosi (cemburu, bingung, marah), subjek M mampu mengekspresikan dua emosi (bingung, marah) dan subjek $\mathrm{M}$ baru mampu mengekspresikan satu emosi (cemburu).

Anak usia 4-5 tahun mulai mampu memahami emosi mereka namun mereka masih perlu banyak belajar terutama tentang penghayatan emosi, penamaan emosi yang dirasakan, bagaimana mengekspresikan emosi diri sendiri dan juga orang orang lain. Kemampuan mereka untuk mengembangkan emosi ini akan sangat membantu mereka dalam kehidupan sosialnya kelak (Papalia, 2001). Anak-anak belajar bagaimana mengekspresikan emosi secara tepat (Denham dkk, 2003 dalam Prosen \& Vitulic, 2017), mencakup peningkatan diferensiasi emosi spesifik dan integrasi berbagai bentuk ekspresi ke dalam gestalt yang dapat dikenali (Camras \& Schutter, 2010 dalam Prosen \& Vitulic, 2017).

Anak-anak prasekolah belajar menggunakan komunikasi emosional, mengekspresikan semua emosi dasar (misalnya bahagia, sedih, marah dan takut), mereka juga dapat menampilkan emosi sosial dan kesadaran diri yang kompleks seperti empati, rasa bersalah, 
kebanggaan, rasa malu dan penghinaan (Denham, 2019). Hal ini sejalan dengan hasil penelitian bahwa pada subjek penelitian telah mampu mengekspresikan jenis emosi-emosi primer dan emosi-emosi yang disadari secara non-verbal (melalui ekspresi wajah dan gesture) namun sebagian subjek masih kesulitan untuk mengekspresikan emosi secara verbal.

Memahami perbedaan berbagai ekspresi emosi membantu anak-anak prasekolah untuk berpikir dan berbicara tentang masalah emosional, termasuk situasi yang menimbulkan emosi (Denham, 1998 dalam Trentacosta, 2020), selain itu kompetensi emosional dalam ekspresi emosi juga berhubungan erat dengan kesuksesan anak di bidang sosial dan akademis (Denham, 2019).

\section{Pemahaman Emosi}

Pemahaman emosi mencakup kemampuan seseorang untuk mengenali dan memberi label emosi seseorang dan emosi orang lain, mengikatnya pada situasi, memahami penyebab emosi mereka, mengidentifikasi aturan tampilan keluarga dan budaya, serta mengenali perbedaan antara tampilan emosional dan emosi yang dirasakan (Campos \& Barret, 1984; Denham, 1998 dalam Leerkes dkk 2008). Pengetahuan tentang emosi memungkinkan anak-anak untuk mengkomunikasikan pengalaman emosional mereka sendiri secara efektif dan merespon dengan tepat ke sinyal emosional orang lain, sehingga meningkatkan kompetensi sosial (Denham dkk, 2003). Pengetahuan anak mengenai emosi akan menghasilkan informasi tentang ekspresi emosional, pengalaman dan kejadian di lingkungan, menyampaikan informasi yang dapat memandu interaksi (Denham, 2019).

Pada penelitian ini diketahui bahwa semua subjek mampu menjelaskan hal-hal apa saja yang membuat mereka merasakan emosi-emosi primer, namun tidak semua mampu memberikan label yang tepat pada emosi-emosi primer. Satu subjek (I) mampu memberikan label yang tepat pada seluruh emosi primer, satu subjek (Z) mampu memberikan label yang tepat sebanyak lima dari enam emosi primer, satu subjek (M) mampu memberikan label tepat pada dua emosi primer dan satu subjek (S) mampu memberikan label tepat pada satu emosi primer.

Pada emosi yang disadari, seluruh subjek mampu menjelaskan hal-hal apa saja yang membuat mereka merasakan emosi yang disadari, namun tidak ada yang mampu memberikan label yang tepat pada seluruh emosi yang disadari. Satu subjek (I) mampu memberikan label 
yang tepat pada tiga (dari enam emosi) emosi yang disadari, dua subjek ( $Z$ dan $S$ ) mampu memberikan label yang tepat pada dua emosi yang disadari, dan satu subjek (M) belum mampu memberikan label pada semua emosi yang disadari.

Pemberian label emosi akan membantu anak mengkomunikasikan emosi yang ia rasakan kepada orangtua ataupun lingkungannya sehingga akan membantu orang tua ataupun guru untuk mengajarkan bagaimana anak-anak mengelola emosinya dengan tepat. Banyak penelitian yang dilakukan (Harre, 1986; Russell, 1990; Saarni, 1999 dalam Bosacki dan Moore 2004) menegaskan bahwa kata-kata atau label emosi memainkan peran yang besar dalam pengembangan konseptualisasi anak. Kopp (1989) menjelaskan bahwa bahasa emosi memberikan pengaruh yang kuat sebagai alat bagi anak untuk memahami emosinya. Widen (2013) menekankan bahwa label emosi lebih dari sekedar kata-kata untuk memberi label ekspresi wajah; setiap label emosi mengacu pada konsep emosi yang menentukan penyebab, konsekuensi perilaku, ekspresi nonverbal, dan label verbal untuk emosi yang diberikan. Label merupakan isyarat yang lebih kuat untuk menggambarkan penyebab emosi daripada ekspresi wajah atau konsekuensi perilaku untuk anak-anak berusia 4 tahun (Salmon dkk, 2013 dalam Christelle dkk, 2019).

Anak-anak prasekolah telah mengembangkan kemampuan verbalnya untuk meningkatkan kemampuannya mengkomunikasikan dan memberikan label terhadap emosinya. Kemampuan anak-anak prasekolah untuk memberi label secara verbal dan mengenali emosi secara verbal meningkat dari usia 2 hingga 4,5 tahun, hanya saja mereka masih memerlukan arahan mengenai pemberian label emosi yang dirasakan (Denham, 1998 dalam Trentacosta, 2020). Hal ini sejalan dengan hasil penelitian yaitu subjek penelitian masih memiliki keterbatasan untuk memberikan label emosi yang dirasakan, bahkan pada emosiemosi dasar yang kerap mereka rasakan. Kurangnya kemampuan anak untuk memahami emosi termasuk memberikan label emosi yang dirasakan membuat anak prasekolah berisiko mengalami agresi, salah mengartikan kemarahan yang mengakibatkan penolakan oleh teman (Denham, 2019). 


\section{Kesimpulan}

Anak usia 4-5 tahun telah memiliki kemampuan untuk mengekspresikan emosiemosi primer maupun emosi-emosi yang disadari secara non verbal melalui gesture dan ekspresi wajah secara tepat, beberapa dari mereka juga sudah mampu mengungkapkan emosi yang disadari secara verbal namun sebagian dari mereka masih belum mampu mengungkapkan emosi secara verbal. Pada kemampuan memberikan label emosi, seluruh subjek memiliki kemampuan sangat terbatas memberikan label yang tepat mulai dari emosi-emosi dasar hingga pada emosi-emosi yang disadari.

\section{Saran}

Mengingat pentingnya anak memiliki kompetensi emosi maka orang tua perlu mengajari anak usia prasekolah untuk memahami dan memberikan label yang tepat pada berbagai emosi-emosi dasar dan emosi yang tidak disadari dan bersikap emotional coaching yang akan membantu anak mengembangkan kompetensi emosinya. Sedangkan bagi sekolah, perlu adanya pembelajaran ataupun program khusus yang lebih terstruktur mengenai kompetensi emosi anak mulai dari pengenalan dan pemberian label emosi secara tepat hingga hal-hal yang berkaitan dengan kompetensi emosi lainnya. Pemberian label emosi ini merupakan dasar bagi anak untuk mengembangkan kompetensi emosinya dan memberikan manfaat dalam kehidupan serta kesehatan psikososialnya kelak.

Penelitian ini masih terbatas pada wawancara yang dilakukan terhadap subjek, guru dan orangtua dan observasi di lingkungan sekolah dalam waktu yang terbatas. Diperlukan observasi dengan waktu yang lebih lama terhadap interaksi subjek baik di sekolah maupun di rumah untuk mendapatkan data yang lebih mendalam mengenai gambaran emosi subjek. Selain itu diperlukan penelitian lebih lanjut mengenai faktorfaktor yang mempengaruhi kompetensi emosional anak prasekolah seperti sikap orang tua ataupun guru yang dapat mendukung atau menghambat kompetensi emosional anak prasekolah. 


\section{Referensi}

Bosacki, S.L., \& Moore, C. (2004). Preschoolers' Understanding of Simple and Complex Emotions: Link With Gender and Language. Sex Roles, 50(9/10), 659-675. doi:10.1023/b:sers.0000027568.26966.27

Carlson, S. M., \& Wang, T. S. (2007). Inhibitory control and emotion regulation in preschool children. Cognitive Development, 22(4), 489-510. doi:10.1016/j.cogdev.2007.08.002.

Christelle, D., Pauline, M., \& Régis, P. (2019). Emotion word comprehension in children aged 4-7 years. The Educational and Developmental Psychologist, 1-6. doi:10.1017/edp.2019.17

Cresswell, John W. (2007). Qualitative Inquiry \& Research Design; Choosing Among Five Approaches Second Edition. United Kingdom : Sage Publication.

Denham, S.A. (2019). Children Emotional Competence,Foundation of Their Success: Skills, Outcomes, And Support. MOV-UP International Conference: Policies, Practices and Qualification in Early Childhood Education.

Denham, S. A. (2019). Emotional Competence During Childhood and Adolescence. Handbook of Emotional Development, 493-541. doi:10.1007/978-3-030-17332-6_20.

Denham, S. A., Bassett, H. H., Way, E., Mincic, M., Zinsser, K., \& Graling, K. (2012). Preschoolers' emotion knowledge: Self-regulatory foundations, and predictions of early school success. Cognition \& Emotion, 26(4), 667679. doi:10.1080/02699931.2011.602049

Denham, S. A., \& Bassett, H. H. (2018). Implications of Preschoolers' Emotional Competence in the Classroom. Emotional Intelligence in Education, 135-171. doi:10.1007/978-3319-90633-1_6

Denham, S. A., Blair, K. A., DeMulder, E., Levitas, J., Sawyer, K., Auerbach-Major, S., \& Queenan, P. (2003). Preschool Emotional Competence: Pathway to Social Competence? Child Development, 74(1), 238-256. doi:10.1111/1467-8624.00533.

Dennis, T. (2006). Emotional self-regulation in preschoolers: The interplay of child approach reactivity, parenting, and control capacities. Developmental Psychology, 42(1), 8497. doi:10.1037/0012-1649.42.1.84

F. Cansu Pala \& Charlie Lewis .(2020). Do preschoolers grasp the importance of regulating emotional expression?. European Journal of Developmental Psychology. DOI: 10.1080/17405629.2020.1814251

Leerkes, E. M., Paradise, M., Calkins, S., O’Brien, M., \& Lange, G. (2008). Emotion and cognition processes in preschool children. Merrill Palmer Quarterly, 54, 102-124.

Morris, A. S., Silk, J. S., Steinberg, L., Myers, S. S., \& Robinson, L. R. (2007). The Role of the Family Context in the Development of Emotion Regulation. Social Development, 16(2), 361-388. doi:10.1111/j.1467-9507.2007.00389.x

Nurmalitasari, Femmi. (2015). Perkembangan Sosial Emosi pada Anak Usia Prasekolah. Yogyakarta. Bultein Psikologi Volume 23 No 2 Desember 2015:103-111. Diakses melalui https://jurnal.ugm.ac.id/buletinpsikologi/article/view/10567/7946. 
Olson, H Matthew \& Hergenhahn, B R.(2011). Pengantar Teori Kepribadian edisi ke-8. Yogyakarta : Pustaka Pelajar.

Papalia, Diane E \& Olds, Sally Wendkos \& Feldman, Ruth Duskin .(2001). Human Development eight edition. New York : Mc Graw-Hill.

Prosen, S., \& Smrtnik Vitulić, H. (2017). Children's emotional expression in the preschool context. Early Child Development and Care, 1-9. doi:10.1080/03004430.2016.1278367

Saarni, Carolyn .(2011). Emotional Development in Childhood. Encyclopedia on Early Childhood Development. USA.Sonoma State University.

Santrok, John W .(2007).Perkembangan Anak edisi kesebelas jilid 2.Jakarta : Erlangga.

Shenton, Andrew K. (2004). Strategies for Ensuring Trustworthiness in Qualitative Research Projects. Education for Information, Vol. 22 (2004), 63-75.

Shields, A., Dickstein, S., Seifer, R., Giusti, L., Dodge Magee, K., \& Spritz, B. (2001). Emotional Competence and Early School Adjustment: A Study of Preschoolers at Risk. Early Education \& Development, 12(1), 7396. doi:10.1207/s15566935eed1201_5

Trentacosta, C. J., \& Crespo, L. M. (2020). Development of Emotional Competence. The Encyclopedia of Child and Adolescent Development, 1-9. doi:10.1002/9781119171492.wecad172

Trentacosta, C. J., \& Fine, S. E. (2010). Emotion Knowledge, Social Competence, and Behavior Problems in Childhood and Adolescence: A Meta-analytic Review. Social Development, 19(1), 1-29. doi:10.1111/j.1467-9507.2009.00543.x

\begin{tabular}{|l|l|l|l|l|}
\hline Submit & Review & Revisi & Diterima & Publis \\
\hline $10-09-2020$ & $05-10-2020$ sd 09-11-2020 & $01-12-2020$ & $03-12-2020$ & $27-1-2021$ \\
\hline
\end{tabular}

Tiara Erlita dan Zainal Abidin

Universitas Padjajaran Bandung

Email : tiara.erlita.psi@gmail.com 